\title{
The Therapeutic Effects of a Progesterone-Releasing Intravaginal Device (PRID) with Attached Estradiol Capsule on Ovarian Quiescence and Cystic Ovarian Disease in Postpartum Dairy Cows
}

\author{
Seungjoon KIM ${ }^{1)}$, Kazuhiro KENGAKU ${ }^{2)}$, Tomomi TANAKA ${ }^{1)}$ and \\ Hideo KAMOMAE ${ }^{1)}$
}

1) Department of Veterinary Medicine, Tokyo University of Agriculture and Technology, Fuchu, Tokyo 183-8509, ${ }^{2}$ Seibu Clinical Center, Chiba Prefectural Federation of Agricultural Mutual Aid Associations, Inba-gun, Chiba 285-0902, Japan

\begin{abstract}
The objective of this study was to evaluate the effects of a progesterone-releasing intravaginal device (PRID) containing an estradiol benzoate capsule on ovarian dysfunction, including ovarian quiescence, follicular cyst (FC) and luteal cyst or cystic corpus luteum (LC/CCL), in postpartum dairy cows. These ovarian dysfunctions were examined by palpation per rectum relative to plasma progesterone status. The results of clinical examination and hormone assay determined ovarian quiescence in 13 cows, FC in 15 cows and LC/CCL in 7 cows. These cows were treated with PRID for $12 \mathrm{~d}$ and then clinical examination was performed. After PRID removal, the proportion of cows exhibiting estrous signs within $7 \mathrm{~d}$ and confirmed formation of CL within 7-14 d (markedly effective) were $69.2 \%(\mathrm{n}=9)$ for ovarian quiescence, $46.7 \%(\mathrm{n}=7)$ for FC, and $28.6 \%$ (2 cows) for LC/ CCL. Two cows (15.4\%) in ovarian quiescence, 5 cows (33.3\%) with FC and 4 cows (57.1\%) with LC/ CCL did not exhibit estrous signs but were recognized as having formed CL within 12-16 d after removal of PRID (effective). These results suggest that treatments of PRID with estradiol benzoate for $12 \mathrm{~d}$ have therapeutic efficacy on ovarian dysfunction including ovarian quiescence, FC and LC/CCL in postpartum dairy cows.
\end{abstract}

Key words: PRID, Ovarian quiescence, Follicular cyst, Luteal cyst or cystic corpus luteum, Dairy cow

(J. Reprod. Dev. 50: 341-348, 2004)

0 varian quiescence and ovarian cyst occur frequently during the postpartum period in dairy cows, and are serious types of ovarian dysfunction causing infertility and delay of rebreeding, resulting in economic loss to farmers [1, 2]. Ovarian quiescence is confirmed by the absence of functional ovulatory follicles and luteal tissues, and blood progesterone concentrations below 1 $\mathrm{ng} / \mathrm{ml}$ in the postpartum period. This condition is a type of anestrus that occurs during the

Accepted for publication: March 8, 2004

Correspondence: H. Kamomae (e-mail: kamomae@cc.tuat.ac.jp) postpartum period and is affected by various factors such as the season, nutrition, suckling conditions and breed $[2,3]$. Ovarian cysts are characterized by the persistent existence of enlarged anovulatory follicles in postpartum dairy cows. The clinical diagnosis of ovarian cyst is based on the reproductive case history, palpation via rectum of a smooth, fluid-filled structure greater than $25 \mathrm{~mm}$ in diameter persisting for 10 days or more, and absence of CL on the surface of the ovary [4-6].

Some previous studies have suggested that 
progesterone-releasing devices have a therapeutic effect on ovarian quiescence and ovarian cysts [710]. In those studies, the progesterone-releasing device was used in combination with GnRH, hCG or $\mathrm{PGF}_{2 \alpha}$ treatment. In addition, a single insertion of a PRID (progesterone-releasing intravaginal device) with or without an attached estradiol capsule has been used for the therapeutic treatment of ovarian quiescence and follicular cyst (FC) [11, 12]. It has been known that estradiol given with PRID has both a luteolytic role as well as a key role in synchronizing follicular waves $[13,14]$.

Until recently, some reports have shown that it is difficult to discriminate between ovarian cyst and cystic corpus luteum (CCL) by rectal palpation [13, 15, 16]. The accuracy of the diagnosis of FC and luteal cyst (LC) by palpation via rectum has been reported to be 58 to $68 \%[9,17]$. LC and CCL have a thicker cystic wall and are usually associated with higher peripheral concentrations of progesterone compared with FC $[16,18]$. Therefore, PRID might be used in cows with LC or CCL in the clinical field, when the primary diagnosis of ovarian function was based on by rectal palpation.

In most cases of ovarian quiescence and FC, PRID insertion induces estrus and ovulation within 7 days after treatment. However, in the case of LC or CCL, the efficacy of PRID insertion is not clear. Currently, PRID has not yet been approved for use in cows in Japan. The present study was designed to evaluate the therapeutic effects and progesterone profiles after a single treatment with a PRID containing an estradiol benzoate capsule on ovarian quiescence and cystic ovarian diseases, including FC, LC or CCL in postpartum dairy cows.

\section{Materials and Methods}

\section{General}

This study was carried out during the period of October 1997 to May 1999 at 30 commercial dairy farms in Chiba Prefecture in Japan. Postpartum dairy cows (Holstein), diagnosed tentatively as ovarian quiescence or cystic ovarian disease were used. They were from 2 to 8 years of age (mean \pm SD: $4.2 \pm 1.5$ years) and 60 to $324 \mathrm{~d}$ postpartum $(141.3 \pm 69.8 \mathrm{~d})$. Their body weights ranged from 475 to $700 \mathrm{~kg}(587 \pm 54.8 \mathrm{~kg})$ and the status of their body condition was fair or good at the time of treatment. All animals were maintained indoors using a tie stall system and were feed on concentrates with hay, silage and water ad libitum.

\section{Diagnoses of ovarian quiescence and cystic ovarian disease}

Cows were examined by experienced veterinary clinicians. The tentative diagnosis of ovarian dysfunction was based on the results of rectal palpation conducted at least twice for the determination of ovarian quiescence and three times for ovarian cyst at 5-7 days intervals. Ovarian quiescence $(n=16)$ was diagnosed when there was neither functional or cyclic corpus luteum (CL), nor cystic follicular structure in ovaries. Cystic ovary $(n=22)$ was initially diagnosed in cows which had a cystic structure greater than $25 \mathrm{~mm}$ in diameter and absence of a functional CL in ovaries examined by palpation via rectum, as described in a previous study $[4,6]$. Final diagnoses were determined based on these observations together with the analyses of progesterone concentrations in blood samples. In 3 of 16 cows (18.2\%) diagnosed as ovarian quiescence by rectal palpation, the progesterone concentration was relatively high $(>1.0 \mathrm{ng} / \mathrm{ml})$ in at least one blood sample collected before PRID treatment.

Table 1. Diagnosis of types of ovarian dysfunction, ovarian quiescence, follicular cyst (FC), and luteal cyst or cystic corpus luteum (LC/CCL), by means of palpation via the rectum compared to serum progesterone classification

\begin{tabular}{cccc}
\hline Diagnosis by palpation & Progesterone concentration & Number of cows & Final diagnosis \\
\hline Ovarian quiescence & $<1 \mathrm{ng} / \mathrm{ml}$ & $13(81.2)^{*}$ & Ovarian quiescence \\
$(\mathrm{n}=16)$ & $\geq 1 \mathrm{ng} / \mathrm{ml}$ & $3(18.8)$ & Ovarian cyclic activity \\
\hline Cystic ovary & $<1 \mathrm{ng} / \mathrm{ml}$ & $15(68.2)$ & FC \\
$(\mathrm{n}=22)$ & $\geq 1 \mathrm{ng} / \mathrm{ml}$ & $7(31.8)$ & LC/CCL \\
\hline
\end{tabular}

${ }^{*}$ Figures in brackets indicate per cent $(\%)$. 
These cows were excluded from the experiments because the ovarian status was assumed to have cyclic activity (Table 1). Cows diagnosed with cystic ovary were finally classified into 2 groups (Table 1). In 15 of 22 cows, the plasma concentration of progesterone was lower than 1 $\mathrm{ng} / \mathrm{ml}$ in all samples collected before PRID treatment, and these cows were diagnosed as FC. In the other cows, a progesterone concentration exceeding $1 \mathrm{ng} / \mathrm{ml}$ was found in at least one sample collected before PRID insertion. We considered that they had functional luteal tissue on the cystic structure of the ovary, and these cows were diagnosed as LC or CCL. However, it is difficult to distinguish CCL from LC clinically by palpation per rectum, when ovulation bulges do not exist on the surface of CCL. Thus, in the present study, they were grouped as LC or CCL (LC/CCL).

\section{Treatment with PRID}

Animals were treated with a progesteronereleasing intravaginal device with an attached capsule containing $10 \mathrm{mg}$ of estradiol benzoate (PRID; CEVA SANTE ANIMALE S.A., France). The PRID was inserted into the vagina after examination of the ovary by rectal palpation (Day 0 ) and was left in the animals for $12 \mathrm{~d}$. After removal of the PRID, signs of estrus were monitored twice daily by the herd owner/manager of each farm for 7 days. The formation of CL in each cow was carefully observed for 16 days by palpation via the rectum to evaluate the therapeutic effect of PRID.

\section{Evaluation of efficacy}

The therapeutic effects of PRID treatment were classified according to the estrous signs and ovarian responses into markedly effective (ME), effective (E) and not effective (NE) as follows. ME: estrous signs appeared within $7 \mathrm{~d}$ after removal of PRID, and the formation of CL (detected by rectal palpation) and an increase in the plasma concentration of progesterone $(\geq 1 \mathrm{ng} / \mathrm{ml})$ were recognized between 7 and $14 \mathrm{~d}$ after PRID removal. E: estrous signs were not exhibited within $7 \mathrm{~d}$ after PRID removal, but the development of CL was confirmed by rectal examination and an increase in plasma concentration of progesterone $(\geq 1 \mathrm{ng} / \mathrm{ml})$ between 12 and $16 \mathrm{~d}$ after PRID removal. NE: there was neither clear estrous sign nor development of
$\mathrm{CL}$ in ovaries during the evaluation period.

\section{Blood sampling and hormone assay}

Blood samples were collected via jugular venipuncture to determine the ovarian steroid profiles prior to PRID insertion (Day -14 and Day -7 for cystic ovarian disease; Day -7 for ovarian quiescence), during PRID treatment (Day 0, Day 23 , Day 12) and after the removal of the PRID (Day 14-15, Day 25-26, Day 31-32 and Day 46-47). Samples were collected in heparinized tubes and placed on ice. Within $1 \mathrm{~h}$ of collection, the samples were centrifuged and the plasma was stored at -20 $C$ until assayed for the concentrations of progesterone and estradiol-17 $\beta$ by a procedure previously described [19].

The sensitivities of the assays were $0.12 \mathrm{pg} / \mathrm{ml}$ for estradiol $-17 \beta$ and $14.5 \mathrm{pg} / \mathrm{ml}$ for progesterone. The intra- and inter-assay coefficients of variation were $3.6 \%$ and $20.7 \%$ for estradiol-17 $\beta$ and $8.7 \%$ and $15 \%$ for progesterone, respectively.

\section{Statistical analyses}

Data were analyzed by analysis of variance (ANOVA) using the StatView computer program (StatView 4.5, Abacus Concepts Inc., Berkeley, CAL, 1995) to determine the significance of differences among therapeutic effects. During PRID treatment, the significance of differences of the mean progesterone concentrations for each diagnostic group was tested using a paired $t$-test.

\section{Results}

In all cows, PRID remained in the vagina until removal and no vaginitis was found clinically throughout the experiment.

\section{Ovarian quiescence}

The therapeutic effects of PRID treatment on ovarian quiescence are summarized in Table 2 . The number of cows in the ME, E and NE groups was 9, 2 and 2, respectively. The plasma progesterone profiles of these groups are shown in Fig. 1. All of the groups with ovarian quiescence showed similar progesterone profiles until the day of PRID removal (Fig. 1, left 3 panels). The plasma progesterone profile after PRID insertion was characterized by an initial increase followed by a gradual decrease and by an immediate decline to 
Table 2. Therapeutic effect of PRID on ovarian dysfunction

\begin{tabular}{lccc}
\hline Diagnosis & \multicolumn{3}{c}{ Efficacy of PRID } \\
& ME & E & NE \\
\hline Ovarian quiescence $(\mathrm{n}=13)$ & $9^{1)}(69.2)^{2)}$ & $2(15.4)$ & $2(15.4)$ \\
$\mathrm{FC}^{3)}(\mathrm{n}=15)$ & $7(46.7)$ & $5(33.3)$ & $3(20.0)$ \\
$\mathrm{LC}^{-\mathrm{CCL}^{4}}(\mathrm{n}=7)$ & $2(28.6)$ & $4(57.1)$ & $1(14.3)$ \\
\hline
\end{tabular}

ME: markedly effective, E: effective, NE: not effective.

${ }^{1)}$ Number of cows. ${ }^{2)}$ Figures in brackets indicate per cent $(\%) .{ }^{3)}$ Follicular cyst. ${ }^{4)}$ Luteal cyst or cystic corpus luteum.

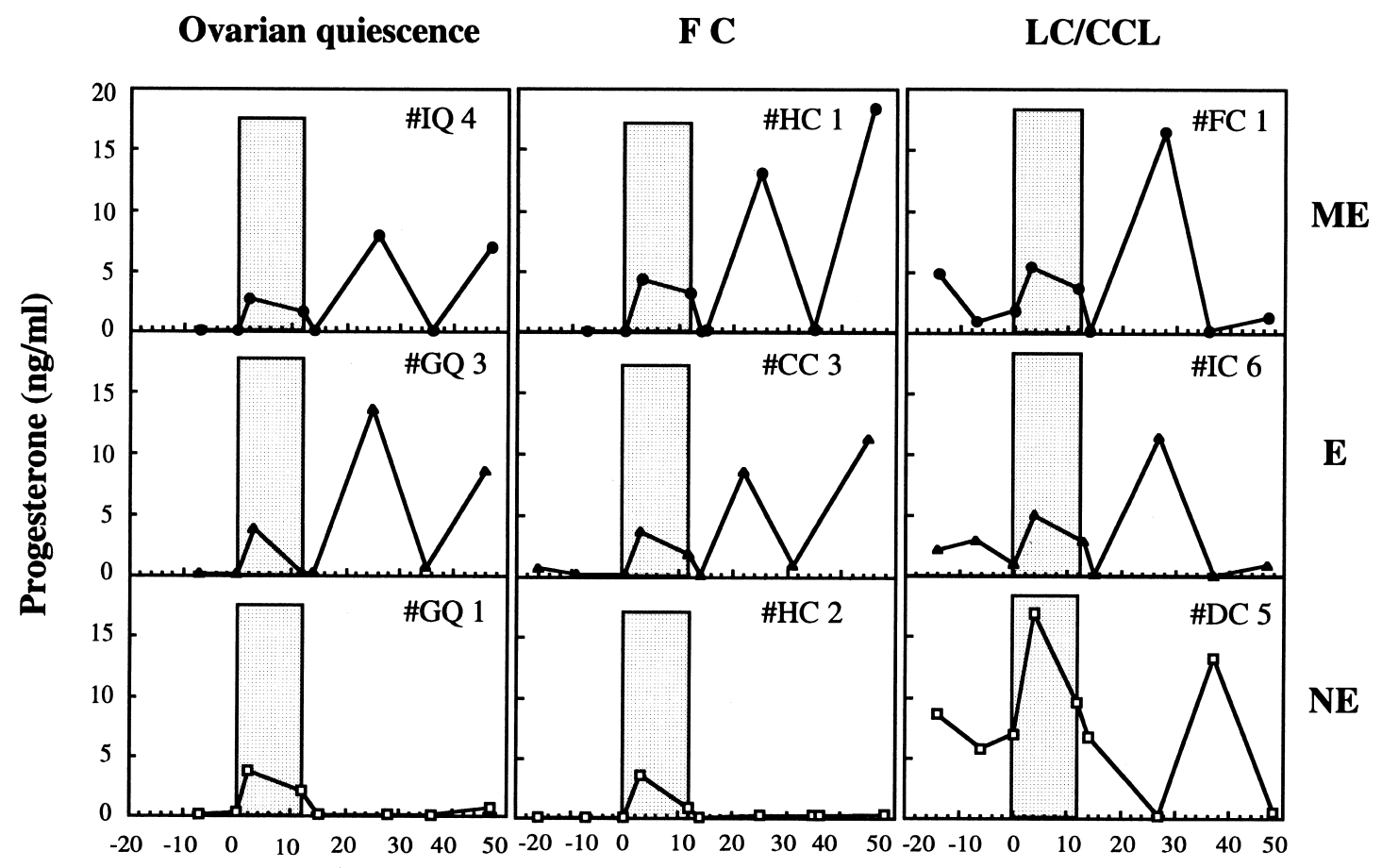

Days from PRID insertion

Fig. 1. Representative patterns of progesterone concentration in cows from the ovarian quiescence (left panels) group, follicular cyst (FC, middle panels) group, and luteal cyst or cystic corpus luteum (LC/CCL, right panels) group classified according to the three therapeutic responses, markedly effective (ME, upper), effective (E, middle) and not effective (NE, bottom). The dotted bars indicate the duration (Days 0-12) of PRID treatment.

the baseline after the withdrawal of the PRID. The concentrations of progesterone on Day 2-3 and on Day 12 were significantly increased during the period of PRID insertion $(\mathrm{p}<0.01)$ compared to those on Day 0 before PRID treatment (Table 3). After removal of the PRID, the progesterone levels in the $\mathrm{ME}$ and $\mathrm{E}$ groups varied with time similarly to those in the normal estrous cycle (Fig. 1, \#IQ4 and \#GQ3), but not in the NE group (Fig. 1, \#GQ1).

The concentrations of estradiol-17 $\beta$ were lower than $5 \mathrm{pg} / \mathrm{ml}$ before PRID treatment in all animals, and showed similar changes to the progesterone concentrations during the PRID insertion (i.e., an initial increase (mean \pm SEM: $9.3 \pm 2.1 \mathrm{pg} / \mathrm{ml}$ ) followed by a decline). After PRID removal, the time-dependent changes in the concentrations of 
Table 3. Plasma concentrations $(\mathrm{ng} / \mathrm{ml})$ of progesterone during the period of PRID insertion in ovarian dysfunction such as ovarian quiescence, follicular cyst (FC), and luteal cyst or cystic corpus luteum (LC/CCL) $)^{1)}$

\begin{tabular}{lccc}
\hline Diagnosis & Day 0 $^{2)}$ & Day 2-3 & Day 12 \\
\hline Ovarian quiescence $(\mathrm{n}=13)$ & $0.3 \pm 0.07$ & $3.8 \pm 0.42^{\mathrm{ab}}$ & $2.1 \pm 0.2^{\mathrm{a}}$ \\
FC $(\mathrm{n}=15)$ & $0.3 \pm 0.06$ & $4.5 \pm 0.44^{\mathrm{ab}}$ & $2.4 \pm 0.17^{\mathrm{a}}$ \\
LC/CCL $(\mathrm{n}=7)$ & $10.0 \pm 2.93$ & $12.4 \pm 2.77^{\mathrm{c}}$ & $2.6 \pm 1.21$ \\
\hline
\end{tabular}

${ }^{1)}$ Data are presented as mean \pm SEM. ${ }^{2}$ Indicates the day of PRID insertion. ${ }^{\text {a Indicates significant }}$ differences from Day $0(P<0.01)$. ' Indicates significant differences from Day $12(P<0.01)$. ' Indicates significant differences from Day $12(P<0.05)$.

estradiol-17 $\beta$ were similar to those in the normal estrous cycle in the ME and E groups, but not in the NE group.

\section{Cystic ovarian disease}

The therapeutic effects of PRID treatment in the FC group are summarized in Table 2. Of the 15 cows, 7 cows were classified as ME, 5 cows as $\mathrm{E}$ and 3 cows as NE. All cows of these groups showed similar progesterone patterns until the day of PRID removal (Fig. 1, middle 3 panels). The concentrations of progesterone on Day 2-3 and on Day 12 were significantly increased after PRID insertion $(p<0.01)$ compared to those on day 0 before PRID treatment (Table 3). After withdrawal of the PRID, the ME and E groups showed similar time-dependent progesterone changes to those seen in the normal estrous cycle (Fig. 1, \#HC1 and \#CC3), whereas the progesterone concentration in the NE group remained at the base line level after PRID removal (Fig. 1, \#HC2).

The therapeutic responses of LC/CCL to PRID treatment are also presented in Table 2. A total of 7 cows with LC/CCL showed the following therapeutic effects: 2 were in the ME group, 4 in the E group and 1 in the NE group. These 3 groups exhibited variable concentrations of progesterone greater than $1 \mathrm{ng} / \mathrm{ml}$ before and during PRID insertion (Fig. 1, right 3 panels). The progesterone levels tended to increase after PRID insertion, but there was no significant difference $(P>0.05)$ between Day 0 and Day 2-3 (Table 3). Then the concentration of progesterone decreased on Day 12 . There was a significant difference $(\mathrm{P}<0.05)$ between Day 2-3 and Day 12. After withdrawal of the PRID, the progesterone concentrations decreased immediately after removal of the PRID in the ME and E groups (Fig. 1, \#FC1 and \#IC6), whereas the cows with NE exhibited a delayed decline of the progesterone levels (Fig. 1, \#DC5). Cyclic changes in the progesterone concentrations were found after the removal of the PRID in all animals of the LC/CCL group.

The circulating concentrations of estradiol-17 $\beta$ were greater than $10 \mathrm{pg} / \mathrm{ml}$ in the FC group and 3 $\mathrm{pg} / \mathrm{ml}$ in the LC/CCL group before PRID treatment. After PRID removal, the timedependent changes of the estradiol-17 $\beta$ concentration were similar to those in the normal estrous cycle in the ME and E groups, but the concentrations were greater than $12 \mathrm{pg} / \mathrm{ml}$ in the FC group and were various in the LC/CCL group until the end of experiment in the NE group.

\section{Discussion}

The results of this study show that the clinical use of a progesterone-releasing device containing an estradiol benzoate capsule induces reliable therapeutic effects on various types of ovarian dysfunction such as ovarian quiescence and FC in postpartum cows. PRID plus estradiol treatment was clearly effective in treating ovarian dysfunction when the device was inserted for 12 days without supplemental treatment. Moreover, it seems that this treatment was able to induce ovulation within several days even in cases of LC or CCL. In previous reports, similar therapeutic effects on cystic ovarian disorders were found in groups treated with a PRID alone, GnRH alone and $\mathrm{PGF}_{2 \alpha}$ alone or with combinations of these agents [9, 12, 20, 21]. Macmillan et al. [22] demonstrated that only 5-7 days of treatment with progesterone followed by estradiol injections could induce estrus and ovulation in anestrous cows. The present 
results support the view that treatment with a PRID including an estradiol bolus alone provides sufficient therapeutic effects on cystic ovary and ovarian quiescence in dairy cows.

Mcleod and Williams [21] as well as Jeffcoate and Ayliffe [12] reported the effectiveness of PRID attached with or without an estradiol capsule on FC in dairy cows. The present results demonstrate that PRID was also effective in 6 of 7 cows diagnosed as LC/CCL. Although the diagnostic information obtained in the present study was insufficient for discriminating between LC and CCL, 3 of these 7 cows seemed to have had CCL, because cyclic changes in their concentrations of progesterone were observed before the PRID treatment (e.g. Fig. 1, right panels, \#FC1). PRID is known to be useful for the synchronization of estrus in cows. It also has been established that the inclusion of an estradiol benzoate capsule to PRID did not directly alter the progesterone secretion from the $\mathrm{CL}$, but it affected the suppression of LH and FSH secretion [23-25]. Furthermore, the suppressed LH and FSH concentrations induced scant luteolytic effect [13]. In the present study, PRID treatment for CCL might have induced the regression of luteal tissue, followed by estrus and ovulation, through negative feedback action on gonadotropin secretion.

Cows treated with PRID showed significant increases in the circulating concentrations of progesterone compared with the pre-treatment levels in cases of ovarian quiescence and FC. The plasma concentrations of progesterone increased markedly to levels from 3 to $6 \mathrm{ng} / \mathrm{ml}$ in 2 to 3 days after intravaginal insertion of the PRID. The peak levels of progesterone during the period of PRID insertion were all within the physiological ranges that are seen in the luteal phase and are known to act on the hypothalamus and anterior pituitary gland to inhibit gonadotropin release [23, 24]. Some studies have suggested that the appearance of estrus within 7 days after PRID removal implies the effectiveness of the device, as shown by the ability of the two ovarian steroids to appropriately influence the hypothalamic-hypophyseal-gonadal axis $[12,23,26]$.
Previous studies have supported the idea that concurrent treatment with progesterone and estradiol is required to terminate a current follicle wave and induce the emergence of a new wave 3-6 days later [14]. The administration of exogenous estradiol with progesterone suppresses the formation or decreases the diameter of the dominant follicle, presumably due to the suppression of FSH and LH via negative feedback action [14, 27]. Several lines of evidence suggest that dysfunction of the hypothalamic gonadotropin-releasing hormone $(\mathrm{GnRH})$ pulse generator and surge generator regulating the pulse and surge modes of gonadotropin secretion are contributing factors in the etiology of ovarian quiescence and FC, respectively [28-30]. It has been established that progesterone induces negative feedback effects on both generators. A plausible mechanism by which PRID might cure both ovarian quiescence and FC is that treatment with a PRID attached to a capsule containing estradiol benzoate induces the renewal of gonadotropin secretion by acting on the hypothalamic $\mathrm{GnRH}$ releasing generators, which in turn induces new follicular development and ovulation and the subsequent formation of corpus luteum, resulting in normal estrous cycles.

In conclusion, the present findings suggest that progesterone and estradiol benzoate treatment administered using a PRID have a high rate of therapeutic effectiveness in cows with reproductive disorders, such as ovarian quiescence, cystic ovary or cystic corpus luteum.

\section{Acknowledgements}

The authors thank Dr. G.D. Niswender of Colorado State University for providing the reagents used in the steroid assays. Thanks are also due to our veterinary associates of the Chiba Prefectural Federation of Agricultural Mutual Aid Associations for the clinical work in this study. This work was partly supported by a grant from the Japan Livestock Technology Association.

\section{References}

1. Lamming GE, Wathes DC, Peters AR. Endocrine patterns of post-partum cow. J Reprod Fertil 1981; 30 (suppl): 155-170.

2. Short RE, Bellows RA, Staigmiller RB, Berardinelli 
JG, Custer EE. Physiological mechanisms controlling anestrus and infertility in postpartum beef cattle. J Anim Sci 1990; 68: 799-816.

3. Randel RD. Nutrition and postpartum rebreeding in cattle. J Anim Sci 1990; 68: 853-862.

4. Yoshioka K, Iwamura S, Kamomae H. Ultrasonic observations on the turnover of ovarian follicular cysts and associated changes of plasma LH, FSH, progesterone and estradiol-17 $\beta$ in cows. Res Vet Sci 1996; 61: 240-244.

5. Cook DL, Smith CA, Parfet JR, Youngquist RS, Brown EM, Garverick HA. Fate and turnover rate of ovarian follicular cysts in dairy cows. J Reprod Fertil 1990; 90: 37-46.

6. Garverick HA. Ovarian follicular cysts in dairy cows. J Dairy Sci 1997; 80: 995-1004.

7. Cavalieri J, Kinder JE, Fitzpatrick LA. Effect of acute treatment with progesterone on the timing and synchrony of ovulation in Bos indicus heifers treated with a norgestomet implant for 17 days. J Reprod Fertil 1998; 112: 249-258.

8. Dailey RA, Inskeep EK, Washburn SP, Price JC. Use of prostaglandin F2 alpha or gonadotropin releasing hormone in treating problem breeding cows. J Dairy Sci 1983; 66: 1721-1727.

9. Kesler DJ, Gaverick HA. Ovarian cysts in dairy cattle: a review. J Anim Sci 1982; 55: 1147-1159.

10. Nanda AS, Ward WR, Williams PC, Dobson $\mathbf{H}$. Retrospective analysis of the efficacy of different hormone treatments of cystic ovarian disease in cattle. Vet Rec 1988; 122: 155-158.

11. Roche JF. Reproductive efficiency in postpartum cows. In: The First Sanofi Sante Nutrition Animale (SSNA) Symposium on Reproduction. France: Bordeaux; 1998: 7-22.

12. Jeffcoate IA, Ayliffe TR. An ultrasonographic study of bovine cystic ovarian disease and its treatment. Vet Rec 1995; 136: 406-410.

13. Thatcher WW, Terqui $\mathbf{M}$, Thimonier J, Mauleon $\mathbf{P}$. Effect of oestradiol-17 $\beta$ on peripheral plasma concentration of 15-keto-13, 14-dihydro PGF $2 \alpha$ and luteolysis in cyclic cattle. Prostaglandins 1986; 31: 745-761.

14. Diskin MG, Austin EJ, Roche, JF. Exogenous hormonal manipulation of ovarian activity in cattle. Domest Anim Endocrinol 2002; 23: 211-228.

15. Nakao T, Sugihashi A, Saga N, Tsunoda N, Kawata K. Use of milk progesterone asaay for differential diagnosis of follicular cyst, luteal cyst, and cystic corpus luteum in cows. Am J Vet Res 1983; 44: 880-890.

16. Sprecher DJ, Nebel RL, Whittier WD. Predictive value of palpation per rectum vs milk and serum progesterone levels for the diagnosis of bovine follicular and luteal cysts. Theriogenology 1988; 30: 701-710.

17. Ax RL, Bellin DK, Schneider DK, Haase-Hardie
JA. Reproductive performance of dairy cows with cystic ovaries following administration of procystin $^{\text {TM }}$. J Dairy Sci 1986; 69: 542-545.

18. Farin RW, Youngquist RS, Parfet JR, Garverick HA. Diagnosis of luteal and follicular ovarian cysts in dairy cows by sector scan ultrasonography. Theriogenology 1990; 34: 633-642.

19. Taya K, Watanabe G, Sasamoto S. Radioimmunoassay for progesterone, testosterone and estradiol-17 $\beta$ using ${ }^{125}$ I-iodohistamine radioligands. Jpn J Anim Reprod 1985; 31: 186-196 (In Japanese).

20. Bartolome JA, Archbald LF, Morresey P, Hernandez J, Tran T, Kelbert D, Long K, Risco CA, Thatcher WW. Comparison of synchronization of ovulation and induction of estrus as therapeutic strategies for bovine ovarian cysts in the dairy cow. Theriogenology 2000; 53: 815-825.

21. Mcleod BJ, Williams ME. Incidence of ovarian dysfunction in post partum dairy cows and the effectiveness of its clinical diagnosis and treatment. Vet Rec 1991; 128: 121-124.

22. Macmillan KL, Taufa VK, Day AM, McDougall S. Some effects of using progesterone and oestradiol benzoate to stimulate oestrus and ovulation in dairy cows with anovulatory anoestrus. Proc NZ Soc Anim Prod 1995; 55: 239-241.

23. Burke CR, Macmillan KL, Boland MP. Oestradiol potentiates a prolonged progesterone-induced suppression of LH release in ovariectomised cows. Anim Reprod Sci 1996; 45: 13-28.

24. Wolfe MW, Roberson MS, Stumpf TT, Kittok RJ, Kinder JE. Circulating concentrations and pattern of luteinizing hormone and follicle-stimulating hormone in circulation are changed by the circulating concentration of $17 \beta$-estradiol in the bovine male and female. J Anim Sci 1992; 70: 248253.

25. Bo GA, Adams GP, Caccia M, Martinez M, Pierson RA, Mapletoft RJ. Ovarian follicular wave emergence after treatment with progesterone and estradiol in cattle. Anim Reprod Sci 1995; 39: 193-204.

26. Calder MD, Salfen BE, Bao B, Youngquist RS, Garverick HA. Administration of progesterone to cows with ovarian follicular cysts results in a reduction in mean $\mathrm{LH}$ and $\mathrm{LH}$ pulse frequency and initiates ovulatory follicular growth. J Anim Sci 1999; 77: 3037-3042.

27. O'Rourke M, Diskin MG, Sreenan JM, Roche JF. The effect of dose and route of oestradiol benzoate administration on plasma concentrations of oestradiol and $\mathrm{FSH}$ in long-term ovariectomized heifers. Anim Reprod Sci 2000; 59: 1-12.

28. Yoshioka K, Iwamura S, Kamomae H. Changes of ovarian structures, plasma LH, FSH, progesterone and estradiol- $17 \beta$ in a cow with ovarian cysts showing spontaneous recovery and relapse. $J$ Vet 
Med Sci 1998; 60: 257-260.

29. Kamomae H, Iwamura S, Yoshioka K, Taniguchi T, Sato M, Tanaka S, Nagasawa S, Shiono $H$, Takahashi Y, Ohashi T, Totoi Y, Hiramatsu M. Clinico-endocrinological, biochemical histopathological analyses on ovarian cyst in cow. Tohoku J Vet Clin 1995; 18: 55-64 (In Japanese).

30. Kamomae H. Therapeutic and physiopathological study on ovarian quiescence in cattle. Jpn J Anim Reprod 1990; 36: 11-22 (In Japanese). 